\title{
THE ERROR REGISTRATION TECHNIQUE FOR MANEUVERING RADAR NETWORK
}

\author{
Liu Yu, Wang Haipeng, Xiong Wei and He You \\ Institute of Information Fusion, Navy Aeronautical and Astronautical University, Yantai, China
}

Received 2013-08-15, Revised 2013-10-19; Accepted 2013-10-29

\begin{abstract}
This study studies are error registration algorithm for the maneuvering radar network, which is one of the difficult problems of multi-sensor registration. When the maneuvering radar has no orientation bias, measurement equations of both attitude bias and measurement bias can be established by using the common targets observed by different radars. Based on the equations, the real-time estimation of both attitude bias and measurement bias can be obtained with the twofold unscented Kalman filter. The results show that the method has a fast convergence rate. When the distance of the sensors is very long, both the absolute registration and the relative registration of attitude bias and measurement bias can be implemented.
\end{abstract}

Keywords: Error Registration, Maneuvering Radar Network, Unscented Transform

\section{INTRODUCTION}

The error registration and compensation technique is one of the prerequisites for multi-sensor fusion (Dong et al., 2004). Recently, lots of error registration algorithms have been proposed, e.g., Real Time Quality Control (RTQC) (Farina and Studer, 1986; Burke, 1996), Neural Network algorithm (Karmiely and Hava, 2000), Maximum Likelihood (ML) (Ong, 2003), Generalized Least Squares (GLS) (Dong et al., 2004), Joint Estimation algorithm based on filtering technique (Yunlong and Guohong, 2005), Least Squares (LS) (Mei et al., 2006), Bias estimation using targets of opportunity (Kragel et al., 2007) and joint registration and tracking (Lian et al., 2011; You et al., 2013). However, the angle error registration and the distance error registration only for stationary sensors are considered in the majority of current research. As far as the ship borne or airborne platforms are considered, the attitude bias and the navigation and orientation bias of the kinetic platforms need to be further researched. Because of the coupling effect of the different types of the biases, the maneuvering sensor registration is hard to be implemented, of which the research fruit is relatively little.
When the sensor platform is moving, Crue et al. (1992) considers the sensor measurement bias and the platform attitude bias simultaneously, but neglects the coupling relationship of the two kinds of the biases. Crue et al. (1992) implements the relative registration of different sensors when the distance between the two radars is very close. Bo et al. (2006) discusses the joint estimation method of the measurement bias and the platform attitude bias based on Kalman filter. Because the Taylor series expansion (linearization) is used to establish the system model, the estimation accuracy will degrade greatly while the system bias increases. Bo et al. (2006) proposes a general method to estimate system bias of each kind of sensors and navigation system based on Nonlinear Least Square. In the method the linearization technique is adapted. Bo et al. (2006) establishes the joint estimation equation of the target state and system bias based on the known target track and discusses the observability problem of the orientation errors, the measurement biases and the emendation biases of 3-D sensors based on UKF filter method.

When 3-D maneuvering radar platform has no orientation error, how to implement the absolute Corresponding Author: Liu Yu, Institute of Information Fusion, Navy Aeronautical and Astronautical University, Yantai, China 
registration of the platform attitude bias and the sensor measurement bias is researched in this study. The study is arranged as follows: The reason of the system error of maneuvering platform senor is discussed in detail at part two, the effective system estimation model is given at part three, the implementation method of bias estimation is discussed at part four and the simulation and analysis is done at part five.

\subsection{The Influence Analysis of Carrier Platform Attitude Bias}

As to the maneuvering radar network, the target measurement from the sensor is usually given in the carrier coordinate, as shown in Fig. 1 (Crue et al., 1992). In order to transform all the target measurements from the different platforms to an uniform coordinate, a transformation of the target measurements from the geographic coordinate to the carrier coordinate should be done based on the carrier platform attitude by (Bo et al., 2006) Equation (1):

$$
r_{b}=\left[\begin{array}{lll}
A_{11} & A_{12} & A_{13} \\
A_{21} & A_{22} & A_{23} \\
A_{31} & A_{32} & A_{33}
\end{array}\right]\left[\begin{array}{c}
X_{g} \\
Y_{g} \\
Z_{g}
\end{array}\right]=A\left[\begin{array}{c}
X_{g} \\
Y_{g} \\
Z_{g}
\end{array}\right]
$$

Where:

$$
\begin{aligned}
& \mathrm{A}_{11}=\cos \vartheta \cos \phi \\
& \mathrm{A}_{12}=\sin \vartheta \cos \phi \\
& \mathrm{A}_{13}=\sin \phi \\
& \mathrm{A}_{21}=\cos \vartheta \sin \phi \sin \alpha-\sin \vartheta \cos \alpha \\
& \mathrm{A}_{22}=\sin \vartheta \sin \phi \sin \alpha+\cos \vartheta \cos \alpha \\
& \mathrm{A}_{23}=\cos \phi \sin \alpha \\
& \mathrm{A}_{31}=\cos \vartheta \sin \phi \cos \alpha+\sin \alpha \sin \vartheta \\
& \mathrm{A}_{32}=\sin \vartheta \sin \phi \cos \alpha-\sin \alpha \cos \vartheta \\
& \mathrm{A}_{33}=\cos \phi \cos \alpha
\end{aligned}
$$

$\vartheta, \phi$ and $\alpha$ are the carrier platform attitudes, respectively express yaw angle, pitch angle and roll angle, which are the three angles between the carrier coordinate and the geographic coordinate.

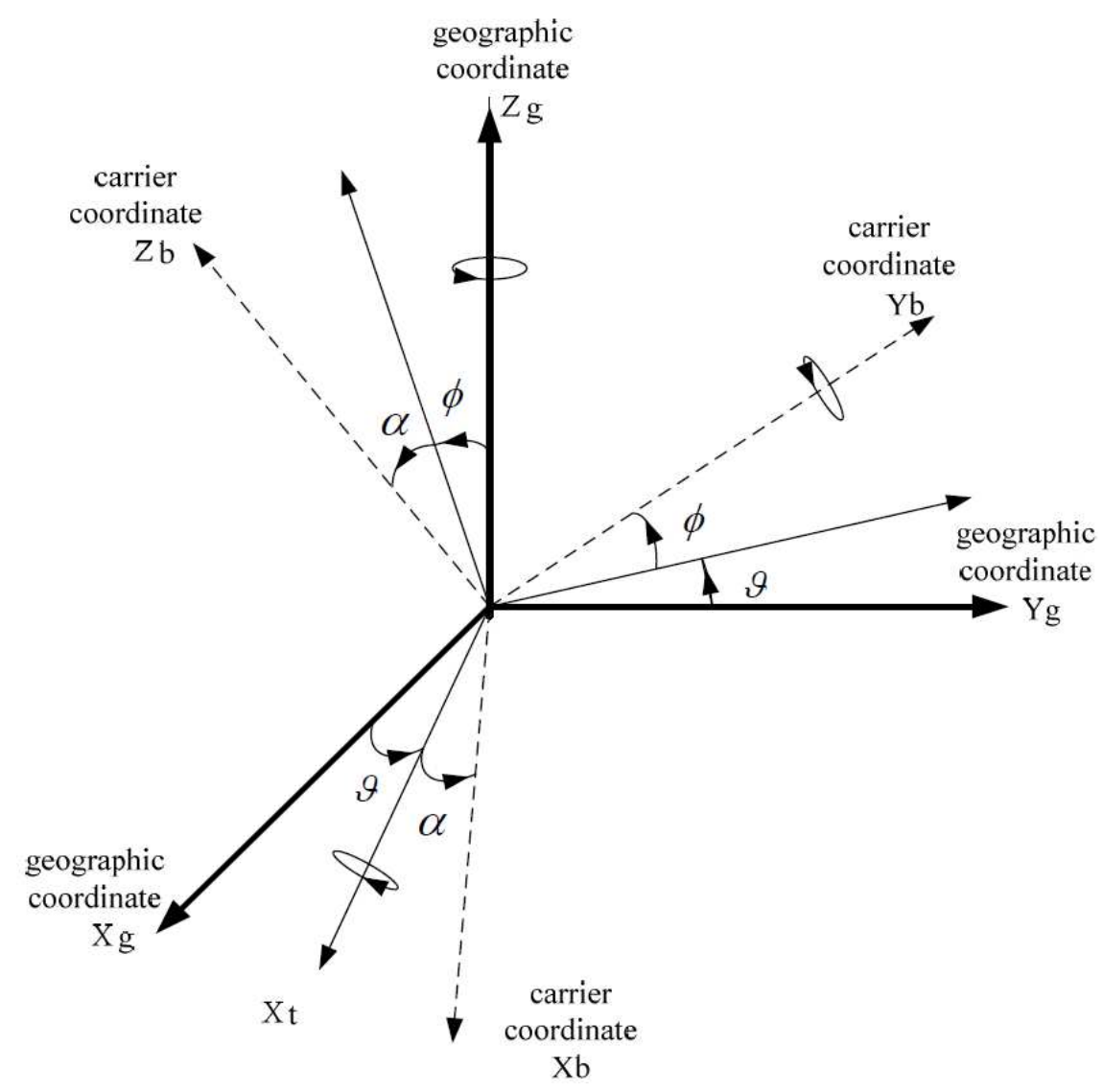

Fig. 1. The transform relationship between the carrier coordinate and geographic coordinate 
If sensor carrier is the stationary platform, the attitude bias is usually considered to be zero. Here, the influence of the transform relationship on the senor bias estimation has nothing more than a calculation burden of coordinate transformation. But for mobile carrier platform such as airplane, vessel and there are always some errors in measuring the attitude of the carrier by the inertial navigation system, platform compass and. Suppose the errors of yaw angle, pitch angle and roll angle can be expressed as Equation (2):

$$
\left\{\begin{array}{l}
\Delta \vartheta=\varepsilon_{\vartheta}+\delta_{\vartheta} \\
\Delta \phi=\varepsilon_{\phi}+\delta_{\phi} \\
\Delta \alpha=\varepsilon_{\alpha}+\delta_{\alpha}
\end{array}\right.
$$

where, $\varepsilon_{\vartheta}, \varepsilon_{\phi}$ and $\varepsilon_{\alpha}$ are expressed as stationary biases, $\delta_{\vartheta}, \delta_{\phi}$ and $\delta_{\alpha}$ are denoted as random biases, which follow the zero-mean gauss distribution.

\subsection{System Model}

Assume there is no orientation errors, the geographic coordinates of radar 1 and radar 2 are respectively supposed to be $\mathrm{P}_{1}\left(\mathrm{~L}_{1}, \lambda_{1}, \mathrm{H}_{1}\right)$ and $\mathrm{P}_{2}\left(\mathrm{~L}_{2}, \lambda_{2}, \mathrm{H}_{2}\right)$.

\subsection{The System Bias State Equation}

Suppose yaw angle bias, pitch angle bias, roll angle bias, the distance bias, azimuth angle bias and elevation angle bias of radar 1 and radar 2 are respectively expressed as $\varepsilon_{\vartheta_{1}}, \varepsilon_{\phi_{1}}, \varepsilon_{\alpha_{1}}, \varepsilon_{\mathrm{r}_{1}}, \varepsilon_{\mathrm{a}_{1}}, \varepsilon_{\mathrm{e}_{1}}$, $\varepsilon_{\vartheta_{2}}, \varepsilon_{\phi_{2}}, \varepsilon_{\alpha_{2}}, \varepsilon_{\mathrm{r}_{2}}, \varepsilon_{\mathrm{a}_{2}}$ and $\varepsilon_{\mathrm{e}_{2}}$. The state equation is established as Equation (3):

$$
\mathrm{X}_{\mathrm{s}}(\mathrm{k}+1)=\mathrm{f}\left[\mathrm{X}_{\mathrm{s}}(\mathrm{k})\right]+\mathrm{V}_{\mathrm{s}}(\mathrm{k})
$$

where, $\mathrm{f}($.$) is the error state transfer equation. \mathrm{V}_{\varepsilon}(\mathrm{k})$ is the course noise random vector which follows the zeromean gauss distribution and $\mathrm{Q}_{\varepsilon}(\mathrm{k})$ is its covariance. $\mathrm{X}_{\varepsilon}(\mathrm{k})$ is the state vector of all the stationary biases at time $\mathrm{k}$, which is defined as:

$$
\mathrm{X}_{\varepsilon}(\mathrm{k}) \triangleq\left[\varepsilon_{\vartheta_{1}}, \varepsilon_{\phi_{1}}, \varepsilon_{\alpha_{1}}, \varepsilon_{\mathrm{r}_{1}}, \varepsilon_{\mathrm{a}_{1}}, \varepsilon_{\mathrm{e}_{1}}, \varepsilon_{\vartheta_{2}}, \varepsilon_{\phi_{2}}, \varepsilon_{\alpha_{2}}, \varepsilon_{\mathrm{r}_{2}}, \varepsilon_{\mathrm{a}_{2}}, \varepsilon_{\mathrm{e}_{2}}\right]
$$

\subsection{The Measurement Equation}

The attitude random error and measurement random error provided by radar 1 are expressed as $\left(\delta_{\vartheta_{1}}, \delta_{\phi_{1}}, \delta_{\alpha_{1}}\right)$ and $\left(\delta_{\mathrm{r}_{1}}, \delta_{\mathrm{a}_{1}}, \delta_{\mathrm{e}_{1}}\right)$, the attitude angle random error and measurement random error provided by radar 2 are expressed as $\left(\delta_{\vartheta_{2}}, \delta_{\phi_{2}}, \delta_{\alpha_{2}}\right)$ and $\left(\delta_{\mathrm{r}_{2}}, \delta_{\mathrm{a}_{2}}, \delta_{\mathrm{e}_{2}}\right)$. Suppose a common target measurement of radar 1 and 2 are respectively $\mathrm{Z}_{1}\left(\mathrm{r}_{1}, \mathrm{a}_{1}, \mathrm{e}_{1}\right)$ and $\mathrm{Z}_{2}\left(\mathrm{r}_{2}, \mathrm{a}_{2}, \mathrm{e}_{2}\right)$ (the local cartesian coordinate). The true target position in the ECEF coordinate, of which the origin is the earth core, is $\mathrm{X}_{\mathrm{t}}\left(\mathrm{x}_{\mathrm{t}}, \mathrm{y}_{\mathrm{t}}, \mathrm{z}_{\mathrm{t}}\right)$. So the corresponding relationship between the measurement of radar 1 and the true target position is given by Equation (4):

$X_{t}=T_{1} A_{1}^{\prime} X_{S_{1}}+P_{T_{1}}$

where, $A_{1}$ is the circumgyration transformation matrix of attitude angle error of radar 1 given by Equation (1). $\mathrm{T}_{1}$ is the circumgyration transformation matrix which transforms the target position from the local cartesian coordinate (radar 1) to the ECEF coordinate. $\mathrm{P}_{\mathrm{T}_{1}}$ is the position of radar 1 in the ECEF coordinate; $\mathrm{X}_{\mathrm{S}_{1}}$ is obtained by removing the measurement error from a measurement of radar 1 and transforming the measurement to the rectangular coordinate, which is given by Equation (5):

$$
\begin{aligned}
& \mathrm{X}_{\mathrm{s}_{1}}=\left[\begin{array}{lll}
\mathrm{x}_{\mathrm{S} 1} & \mathrm{y}_{\mathrm{s}_{1}} & \mathrm{z}_{\mathrm{s}_{1}}
\end{array}\right] \\
& =\left[\begin{array}{c}
\left(\mathrm{r}_{1}-\varepsilon_{\mathrm{r}_{1}}-\delta_{\mathrm{r}_{1}}\right) \cos \left(\mathrm{e}_{1}-\varepsilon_{\mathrm{e}_{1}}-\delta_{\mathrm{e}_{1}}\right) \sin \left(\alpha_{1}-\varepsilon_{\mathrm{a}_{1}}-\delta_{\mathrm{a}_{1}}\right) \\
\left(\mathrm{r}_{1}-\varepsilon_{\mathrm{r}_{1}}-\delta_{\mathrm{r}_{1}}\right) \cos \left(\mathrm{e}_{1}-\varepsilon_{\mathrm{e}_{1}}-\delta_{\mathrm{e}_{1}}\right) \cos \left(\alpha_{1}-\varepsilon_{\mathrm{a}_{1}}-\delta_{\mathrm{a}_{1}}\right) \\
\left(\mathrm{r}_{1}-\varepsilon_{\mathrm{r}_{1}}-\delta_{\mathrm{r}_{1}}\right) \sin \left(\mathrm{e}_{1}-\varepsilon_{\mathrm{e}_{1}}-\delta_{\mathrm{e}_{1}}\right)
\end{array}\right] \\
& =\mathrm{h}_{1}\left(\mathrm{Z}_{1}, \varepsilon_{\mathrm{Z}_{1}}, \delta_{\mathrm{Z}_{1}}\right)
\end{aligned}
$$

where, $\mathrm{h}_{1}($.$) is defined as the measurement transform$ function from the polar coordinate to the rectangular coordinate; $\varepsilon_{\mathrm{z}_{1}}$ and $\delta_{\mathrm{z}_{1}}$ are respectively the measurement bias vector and random error vector of radar 1 .

If $X_{t}$ is transformed to the true measurement polar coordinate of radar 2 , the corresponding relation between the measurements from radar 2 and the true target positions is Equation (6):

$$
\mathrm{Z}_{2}=\mathrm{h}_{2}\left[\mathrm{~A}_{2} \mathrm{~T}_{2}{ }^{\prime}\left(\mathrm{X}_{\mathrm{t}}-\mathrm{P}_{\mathrm{T}_{2}}\right)\right]+\varepsilon_{\mathrm{Z}_{2}}+\delta_{\mathrm{Z}_{2}}
$$


where, $\mathrm{A}_{2}$ is the circumgyration transformation matrix of attitude angle error of radar 2 given by (1). $T_{2}$ is the circumgyration transformation matrix which transforms the target position from the local cartesian coordinate (radar 2) to the ECEF coordinate. $\mathrm{P}_{\mathrm{T}_{2}}$ is the position of radar 2 in the ECEF coordinate. $\varepsilon_{\mathrm{z}_{2}}$ and $\delta_{\mathrm{z}_{2}}$ are respectively the measurement bias vector and random error vector of radar $2 . \mathrm{h}_{2}(\bullet)$ is defined as the measurement transform function from the rectangular coordinate to the polar coordinate, as follows Equation (7):

$$
\mathrm{h}_{2}(\mathrm{X}) \triangleq\left[\begin{array}{c}
\sqrt{\mathrm{x}^{2}+\mathrm{y}^{2}+\mathrm{z}^{2}} \\
\arctan (\mathrm{x} / \mathrm{y}) \\
\arctan \left(\mathrm{z} / \sqrt{\mathrm{x}^{2}+\mathrm{y}^{2}+\mathrm{z}^{2}}\right)
\end{array}\right]
$$

where, $\mathrm{X}(\mathrm{x}, \mathrm{y}, \mathrm{z})$ expresses the 3-D coordinate value of the target in the rectangular coordinate.

Based on (4) and (6), the system bias measurement equation at time $\mathrm{k}$ is established as:

$$
\begin{aligned}
\mathrm{Z}_{2}(\mathrm{k}) & =\mathrm{h}_{2}\left\{\mathrm{~A}_{2}(\mathrm{k}) \mathrm{T}_{2}^{\prime}(\mathrm{k})\right. \\
& \cdot\left[\mathrm{T}_{1}(\mathrm{k}) \mathrm{A}_{1}^{\prime}(\mathrm{k}) \mathrm{h}_{1}\left(\mathrm{Z}_{1}(\mathrm{k}), \varepsilon_{\mathrm{z}_{1}}(\mathrm{k}), \delta_{\mathrm{z}_{1}}(\mathrm{k})\right)\right. \\
& \left.\left.+\mathrm{P}_{\mathrm{T}_{1}}(\mathrm{k})-\mathrm{P}_{\mathrm{T}_{2}}(\mathrm{k})\right]+\varepsilon_{\mathrm{z}_{2}}(\mathrm{k})+\delta_{\mathrm{z}_{2}}(\mathrm{k})\right\}
\end{aligned}
$$

Equation (8) can be further simplified as Equation (9):

$$
\mathrm{Z}_{2}(\mathrm{k})=\mathrm{h}\left(\mathrm{X}_{\varepsilon}(\mathrm{k}), \mathrm{Z}_{1}(\mathrm{k}), \delta_{\varepsilon_{1}}(\mathrm{k}), \delta_{\varepsilon_{2}}(\mathrm{k}), \delta_{\mathrm{z}_{1}}(\mathrm{k})\right)+\delta_{\mathrm{Z}_{2}}(\mathrm{k})
$$

where, $\delta_{\varepsilon_{1}}(\mathrm{k})$ and $\delta_{\varepsilon_{2}}(\mathrm{k})$ express the attitude angle random error vectors of radar 1 and radar 2 respectively.

\subsection{The Bias Estimation Method}

The measurement equation defined by (9) is a complex nonlinear equation. If the extended Kalman filter is applied, the linearization error is so large that the estimation result can't meet the accuracy requirement. This part will discuss how to obtain the efficient bias estimation by using the Unscented Kalman Filter.
Suppose the state estimation vector and the state covariance are $\hat{\mathrm{X}}_{\varepsilon}(\mathrm{k})$ and $(\mathrm{k}) \mathrm{P}_{\varepsilon}$ respectively at time $\mathrm{k}$, then $2 n_{x}+1\left(n_{x}\right.$ is the dimension of system state vector) sampling point $\xi_{\mathrm{i}}(\mathrm{k} \mid \mathrm{k})$ and their corresponding weight i W can be computed with the Unscented Transform method in (Julier and Uhlmann, 2000). According to (3), the one-step prediction of all the sampling points can be obtained by Equation (10):

$$
\xi_{\mathrm{i}}(\mathrm{k}+1 \mid \mathrm{k})=\mathrm{f}\left[\xi_{\mathrm{i}}(\mathrm{k} \mid \mathrm{k})\right]
$$

With the one-step prediction of sampling point $\xi_{\mathrm{i}}(\mathrm{k}+1 \mid \mathrm{k})$ and its weight $\mathrm{W}_{\mathrm{i}}$, the predicted error state estimation and the predicted covariance can be obtained as Equation (11):

$$
\hat{\mathrm{X}}_{\varepsilon}(\mathrm{k}+1 \mid \mathrm{k})=\sum_{\mathrm{i}=0}^{2 \mathrm{n}_{\mathrm{x}}} \mathrm{W}_{\mathrm{i}} \xi_{\mathrm{i}}(\mathrm{k}+1 \mid \mathrm{k})
$$

And Equation (12):

$$
\begin{aligned}
& \mathrm{P}_{\varepsilon}(\mathrm{k}+1 \mid \mathrm{k})=\mathrm{Q}_{\varepsilon}(\mathrm{k}) \\
& +\sum_{\mathrm{i}=0}^{2 \mathrm{n}_{\mathrm{X}}} \mathrm{W}_{\mathrm{i}} \Delta \mathrm{X}_{\mathrm{i}}(\mathrm{k}+1 \mid \mathrm{k}) \Delta \mathrm{X}_{\mathrm{i}}^{\prime}(\mathrm{k}+1 \mid \mathrm{k})
\end{aligned}
$$

Where:

$$
\Delta \mathrm{X}_{\mathrm{i}}(\mathrm{k}+1 \mid \mathrm{k})=\xi_{\mathrm{i}}(\mathrm{k}+1 \mid \mathrm{k})-\hat{\mathrm{X}}_{\varepsilon}(\mathrm{k}+1 \mid \mathrm{k})
$$

The random measurement error is usually independent of the nonlinear equation. However, the random measurement error in (9) is different from the observation models in the other references, which is not independent of the nonlinear equation. The conventional Unscented Kalman Filter can't deal with this problem.

Define $\delta_{\varepsilon}(\mathrm{k}) \triangleq\left[\delta_{\varepsilon_{1}}(\mathrm{k}), \delta_{\varepsilon_{2}}(\mathrm{k}), \delta_{\mathrm{z}_{2}}(\mathrm{k})\right]^{\prime}$ as a new error vector, where $R_{\varepsilon}$ is its error covariance. Based on unscented transform, $2 \mathrm{~m}_{\mathrm{x}}+1\left(\mathrm{~m}_{\mathrm{x}}\right.$ is the dimension of vector $\left.\delta_{\varepsilon}(\mathrm{k})\right)$ sampling points for $\delta_{\varepsilon}(\mathrm{k})$ is done. Suppose $\delta_{\varepsilon j}(\mathrm{k}+1)$ and $\mathrm{E}_{\mathrm{j}}$ express the sampling points and their weight respectively. The calculation equations in detail are as follows.

Assume the one-step prediction of each sampling point $\xi_{\mathrm{i}}(\mathrm{k}+1 \mid \mathrm{k})$ as the center. Another equation could be 
obtained by applying all the sampling points of $\delta_{\varepsilon}(\mathrm{k})$ in measurement (9):

$$
\varsigma_{\mathrm{ij}}(\mathrm{k}+1 \mid \mathrm{k})=\mathrm{h}\left(\xi_{\mathrm{i}}(\mathrm{k}+1 \mid \mathrm{k}), \delta_{\mathrm{\varepsilon j}}(\mathrm{k}+1)\right)
$$

Consequently, the predicted measurement and covariance corresponding to $\xi_{\mathrm{i}}(\mathrm{k}+1 \mid \mathrm{k})$ can be obtained as:

$$
\zeta_{\mathrm{i}}(\mathrm{k}+1 \mid \mathrm{k})=\sum_{\mathrm{j}=0}^{2 \mathrm{~m}_{\mathrm{x}}} \mathrm{E}_{\mathrm{j}} \varsigma_{\mathrm{ij}}(\mathrm{k}+1 \mid \mathrm{k})
$$

And:

$$
\mathrm{P}_{\zeta_{\mathrm{i}}}=\sum_{\mathrm{j}=0}^{2 \mathrm{~m}_{\mathrm{x}}} \mathrm{E}_{\mathrm{j}} \Delta \zeta_{\mathrm{ij}}(\mathrm{k}+1 \mid \mathrm{k}) \Delta \zeta_{\mathrm{ij}}^{\prime}(\mathrm{k}+1 \mid \mathrm{k})
$$

Where:

$$
\Delta \zeta_{\mathrm{ij}}(\mathrm{k}+1 \mid \mathrm{k})=\zeta_{\mathrm{ij}}(\mathrm{k}+1 \mid \mathrm{k})-\zeta_{\mathrm{i}}(\mathrm{k}+1 \mid \mathrm{k})
$$

Equation 13-15 apply the theory of Unscented Transform, implement the accurate transfer of the measurement random error with the spread of the measurement function (9) and calculate the first rank and the second rank statistic characteristics of the random vector, namely the predicted measurement mean and its covariance. If the background follows Gauss distribution, the precision of the mean and the covariance from Unscented Transform can get to the second rank and the process in detail is referred in (You et al., 2005).

Based on (14) and (15), the predicted measurement and the corresponding covariance can be obtained according to the follow formula Equation (16 and 17):

$$
\begin{aligned}
& \hat{\mathrm{Z}}(\mathrm{k}+1 \mid \mathrm{k})=\sum_{\mathrm{i}=0}^{2 \mathrm{n}_{\mathrm{X}}} \mathrm{W}_{\mathrm{i}} \varsigma_{\mathrm{i}}(\mathrm{k}+1 \mid \mathrm{k}) \\
& \mathrm{P}_{\mathrm{zz}}=\mathrm{R}_{\mathrm{z}_{2}}+\sum_{\mathrm{i}=0}^{2 \mathrm{n}_{\mathrm{X}}} \mathrm{W}_{\mathrm{i}}\left(\mathrm{P}_{\mathrm{si}_{\mathrm{i}}}+\Delta \mathrm{Z}_{\mathrm{i}} \Delta \mathrm{Z}_{\mathrm{i}}^{\prime}\right)
\end{aligned}
$$

where, $\mathrm{R}_{\mathrm{z}_{2}}$ is the covariance of measurement random error of radar 2 Equation (18):

$$
\Delta \mathrm{Z}_{\mathrm{i}}=\varsigma_{\mathrm{i}}(\mathrm{k}+1 \mid \mathrm{k})-\hat{\mathrm{Z}}(\mathrm{k}+\mid \mathrm{k})
$$

Similarly, the interactive covariance between the measurement vector and the bias vector can be gotten by Equation (19):

$$
\mathrm{P}_{\mathrm{xz}}=\sum_{\mathrm{i}=0}^{2 \mathrm{n}_{\mathrm{X}}} \mathrm{W}_{\mathrm{i}} \Delta \mathrm{X}_{\mathrm{i}}(\mathrm{k}+1 \mid \mathrm{k}) \Delta \mathrm{Z}_{\mathrm{i}}^{\prime}
$$

Finally, the bias estimation state update and covariance are respectively Equation (20 and 21):

$$
\hat{\mathrm{X}}_{\varepsilon}(\mathrm{k}+1)=\hat{\mathrm{X}}_{\varepsilon}(\mathrm{k}+1 \mid \mathrm{k})+\mathrm{K}(\mathrm{k}+1)(\mathrm{Z}(\mathrm{k}+1)-\mathrm{Z}(\mathrm{k}+1 \mid \mathrm{k}))
$$

And:

$$
\mathrm{P}_{\varepsilon}(\mathrm{k}+1)=\mathrm{P}_{\varepsilon}(\mathrm{k}+1 \mid \mathrm{k})-\mathrm{K}(\mathrm{k}+1) \mathrm{P}_{\mathrm{zz}} \mathrm{K}^{\prime}(\mathrm{k}+1)
$$

where, $\mathrm{K}(\mathrm{k}+1)=\mathrm{P}_{\mathrm{xz}} \mathrm{P}_{\mathrm{zz}}^{-1}$.

\subsection{Simulation Analysis}

The simulation results when sensors are far away from each other.

Assume that radar 1 is located at $(120.000,30.200$, $100 \mathrm{~m})$ and radar 2 is located at $(120.500,30.000,0 \mathrm{~m})$. The sample interval of radar is one second. Every kind of errors is stationary errors, which are shown as Table $\mathbf{1 .}$

Suppose there are two observable targets in the surveillance area. The initialization states of the two targets in the ECEF coordinate are supposed to be (in meters) $X_{1}=[-2800000 ; 50 ; 4800000 ; 85 ; 3120000 ; 0]$ and $X_{2}=[-2780000 ; 100 ; 4750000 ;-150 ; 3220000 ; 0]$.

Figure 2-5 are the RMS curves of the attitude bias estimation and the measurement bias estimation of radar 1 and radar 2, obtained by Monte Carlo simulations with 20 runs. The length of each run is 120. In all simulations, the initialization state of estimation is supposed to be 0 . According to the simulation results, bias estimation almost converges after 20 steps. The biggest error of all the angle bias estimations is roll angle bias estimation, which is up to $52.1 \%$; the smallest error is yaw angle bias estimation, which is merely $7.1 \%$. What is more, the distance bias of radar 2 is up to $91.8 \%$. The reason is that the influence of angle bias to the radar detection is relatively big. The distance bias of radar is relatively small and is easily submerged by the other biases, which can influence the precision of the estimation error (The distance bias of radar 1 is merely $18.4 \%$ ). 
Liu Yu et al. / Journal of Computer Science 9 (12): 1648-1660, 2013

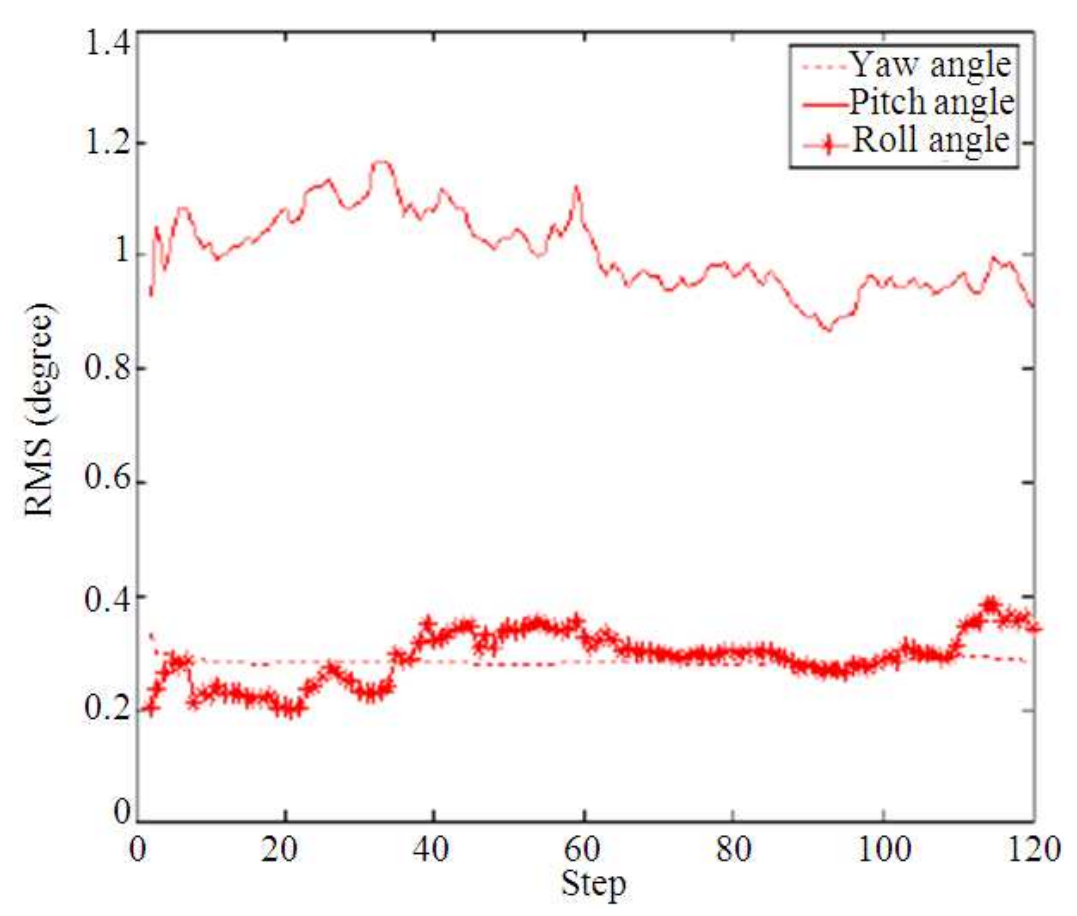

Fig. 2. The attitude bias RMS of radar 1

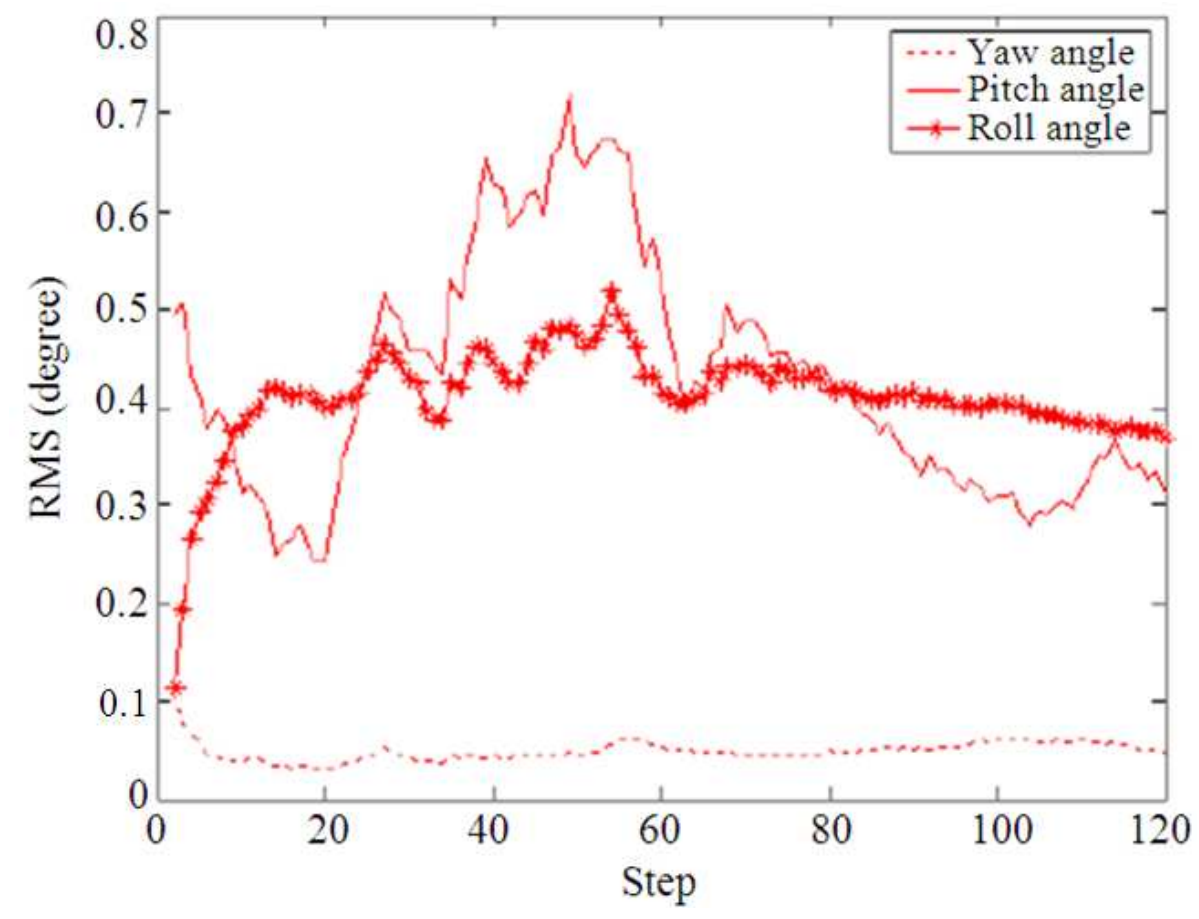

Fig. 3. The attitude bias RMS of radar 2 
Liu Yu et al. / Journal of Computer Science 9 (12): 1648-1660, 2013

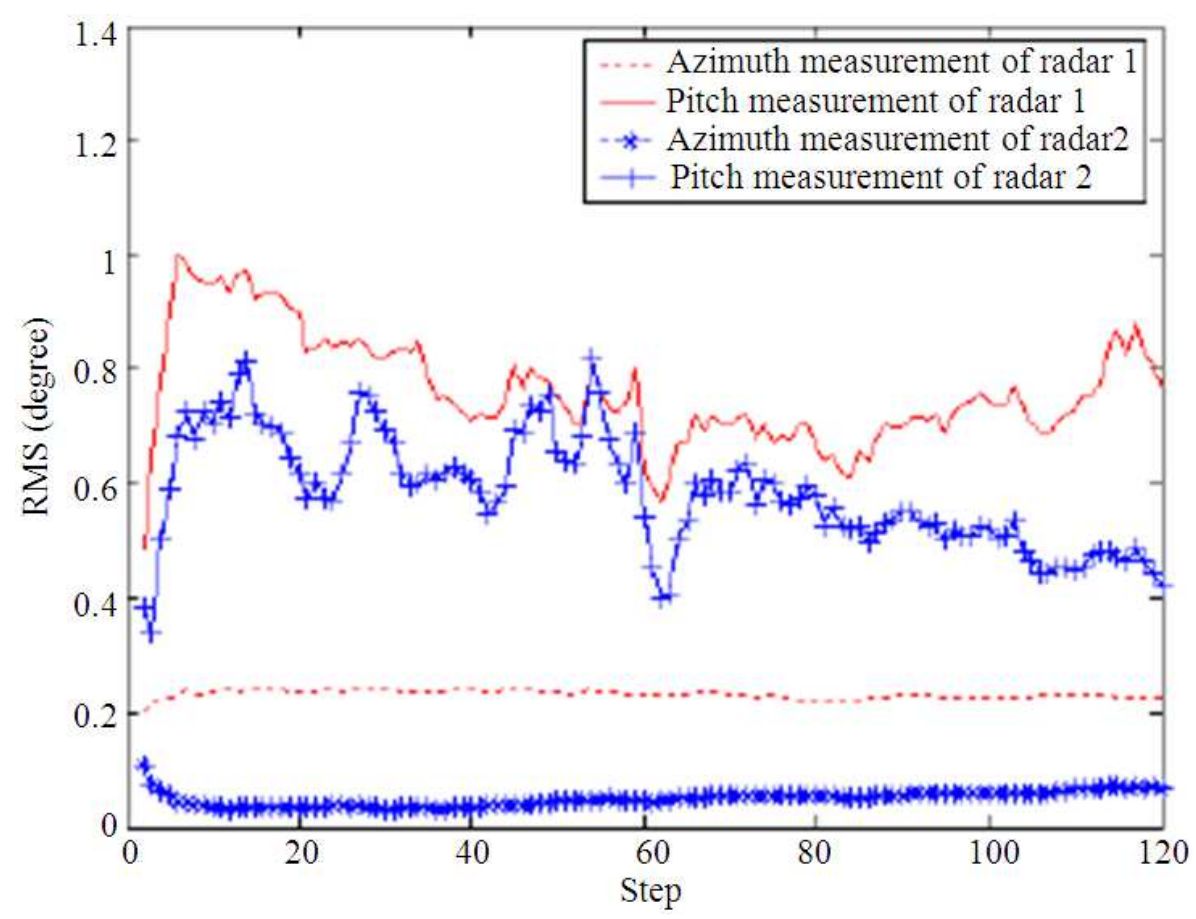

Fig. 4. The angle bias RMS of radar 1 and 2

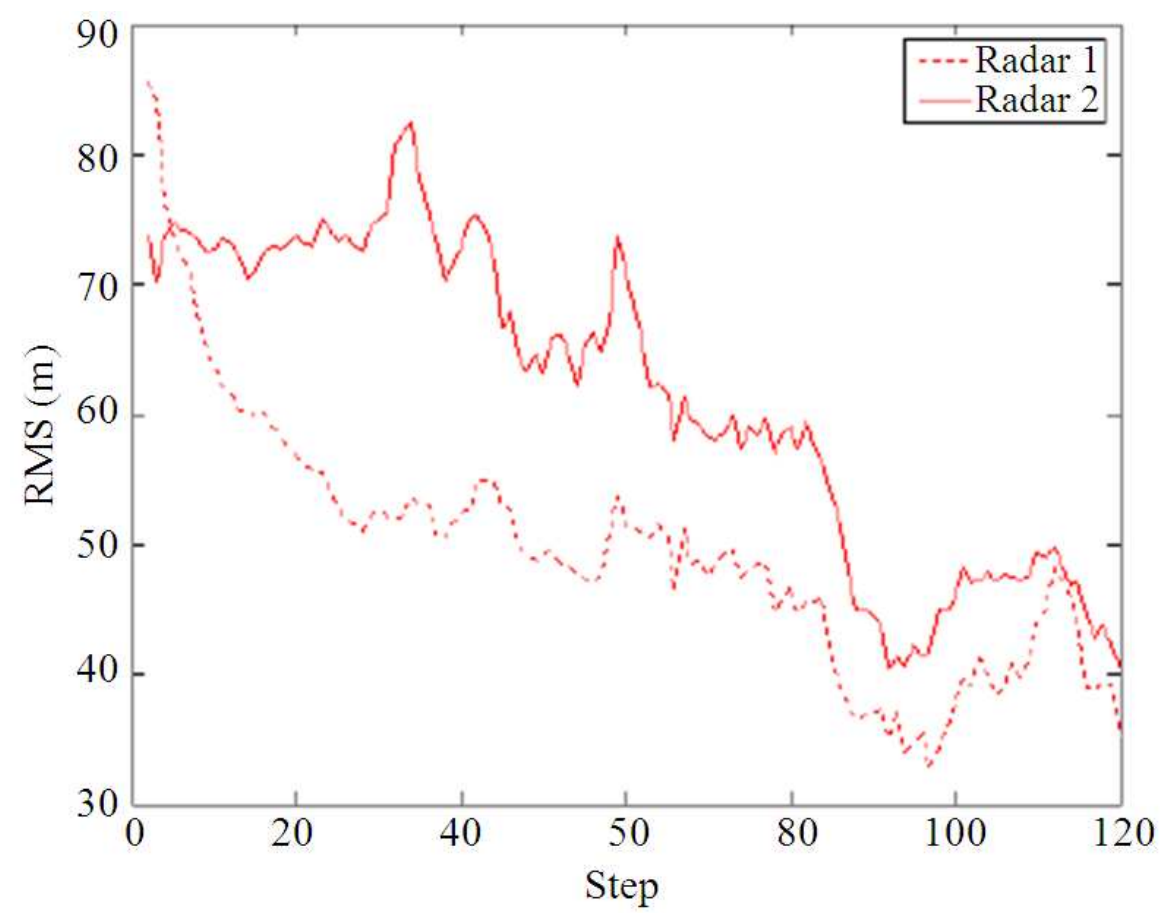

Fig. 5. The range bias RMS of radar 1 and 2 
Liu Yu et al. / Journal of Computer Science 9 (12): 1648-1660, 2013

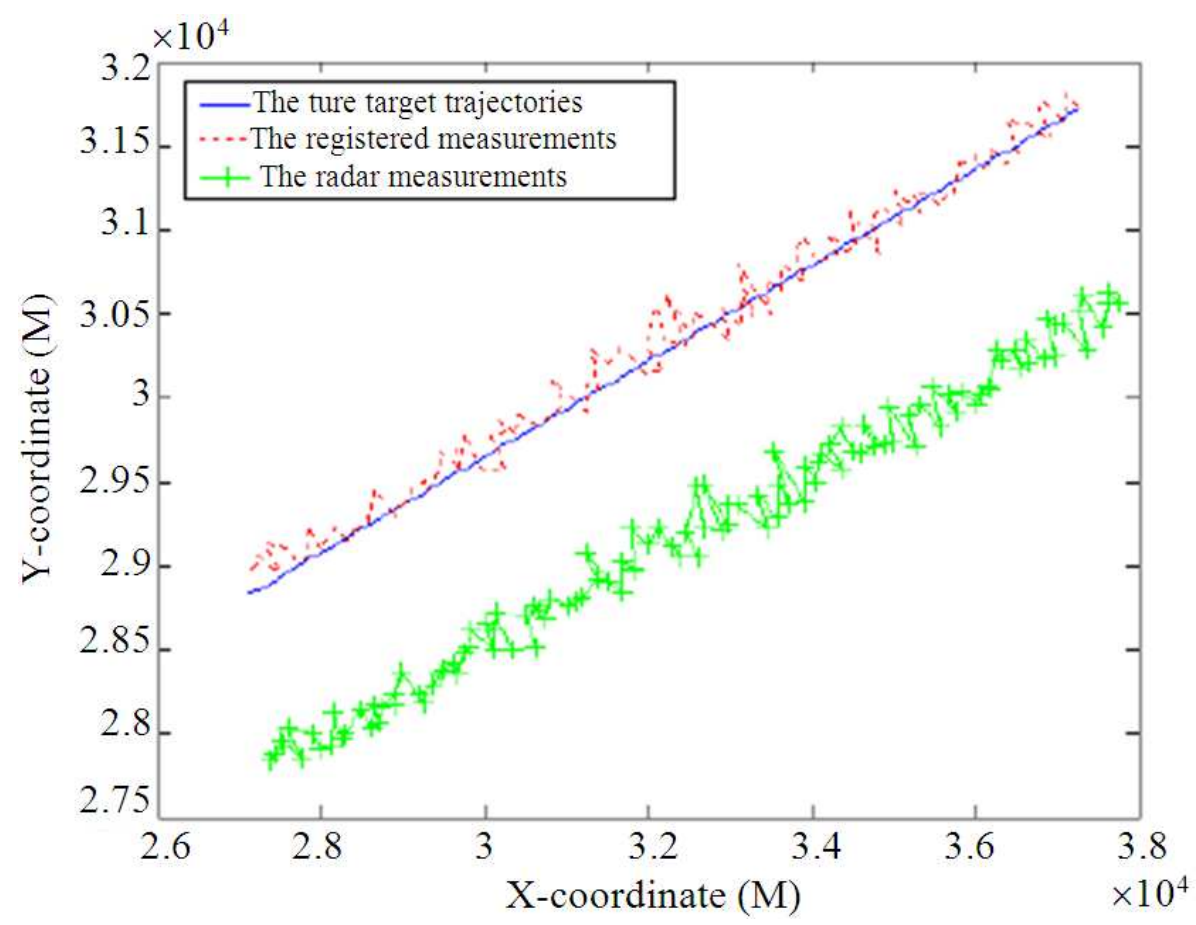

Fig. 6. The target 1 trajectory

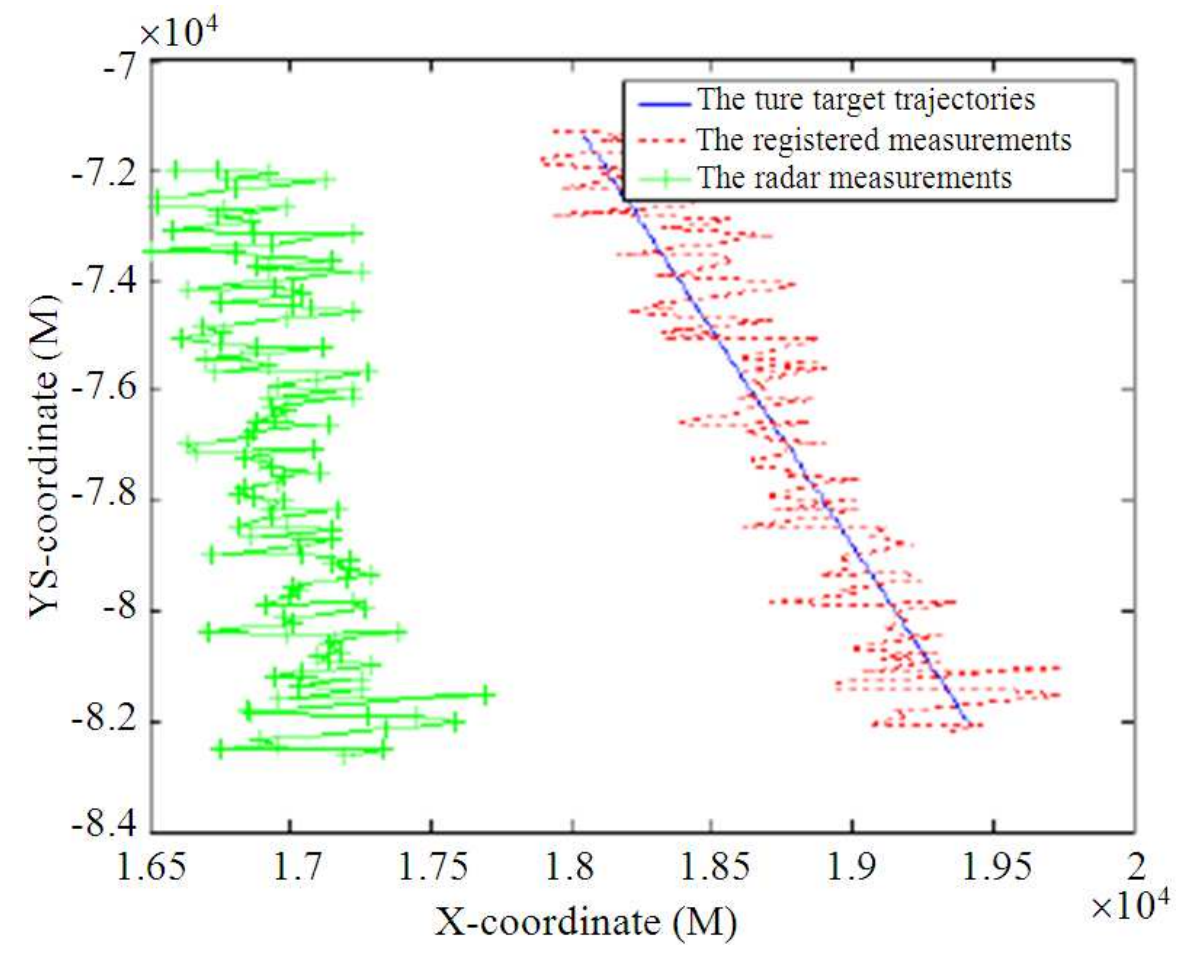

Fig. 7. The target 2 trajectory 
Liu Yu et al. / Journal of Computer Science 9 (12): 1648-1660, 2013

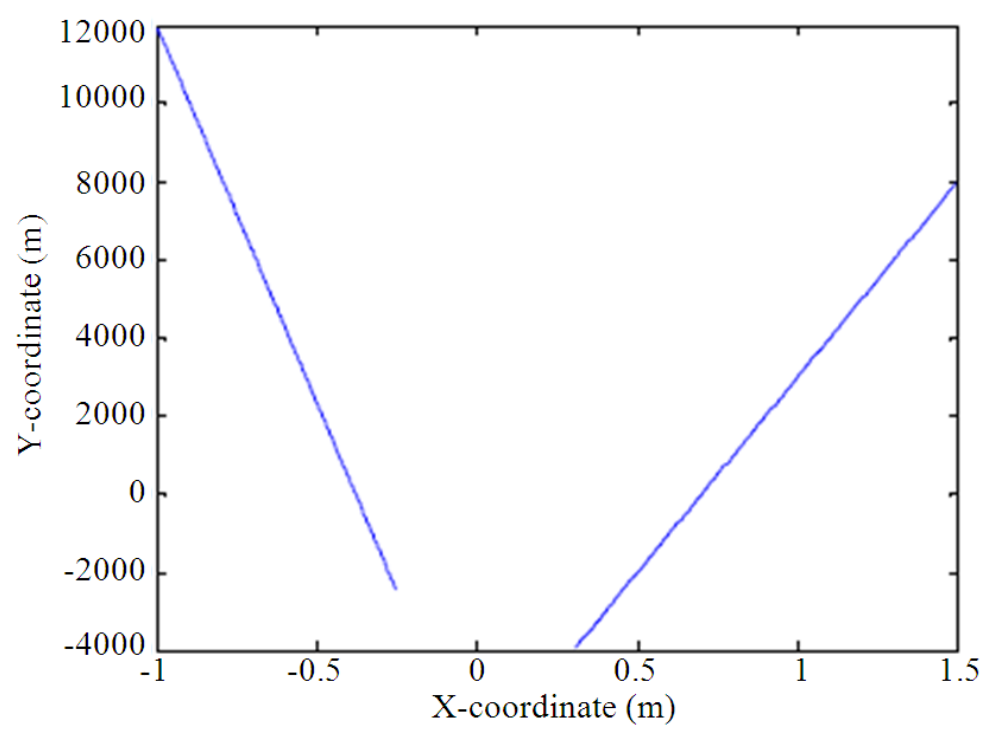

Fig. 8. Track coordinates in xy-plane

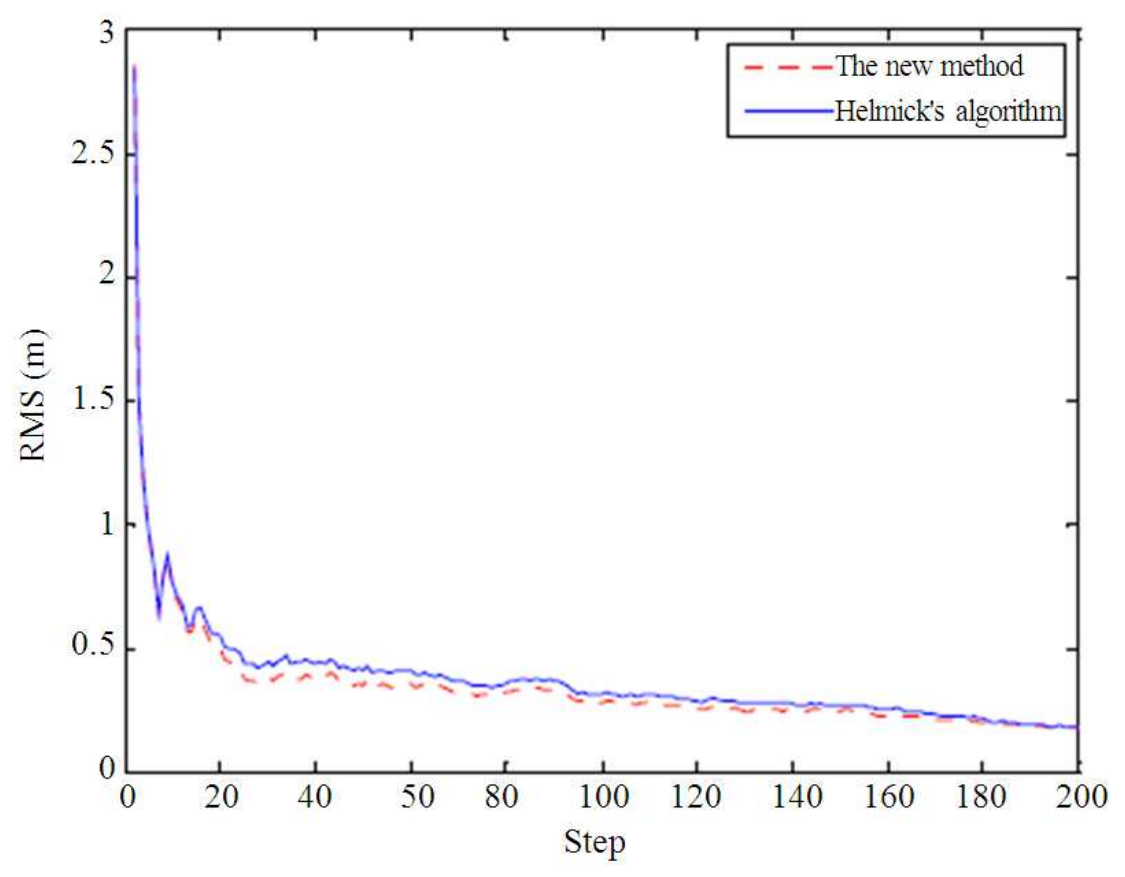

Fig. 9. Range bias estimatesn

Table 1. The parameter setting of radar error

\begin{tabular}{lll}
\hline & Radar 1 & Radar 2 \\
\hline Attitude bias & $(10 ; 20 ;-10)$ & $(-10 ; 10 ; 1.50)$ \\
Measurement bias & $(100 \mathrm{~m} ;-0.50 ; 10)$ & $(50 \mathrm{~m} ; 10 ;-20)$ \\
Attitude random error & $(0.10 ; 0.20 ; 0.10)$ & $(0.20 ; 0.10 ; 0.10)$ \\
Measurement random error & $(10 \mathrm{~m} ; 0.10 ; 0.10)$ & $(10 \mathrm{~m} ; 0.10 ; 0.10$ \\
\hline
\end{tabular}

Figure 6 and 7 show the true target tracks, the radar measurements tracks and the registered measurements tracks, which are generated in real-time in the local Cartesian coordinates of radar 1 . In order to compensating the biases, the present bias estimation is directly used. As to Fig. 6 and 7, the measurement tracks 
can be effectively modified with the error compensation of the bias estimations to the sensors even before all the bias estimation converges wholly. This example also illustrates the estimation accuracy of range bias has little influence on the registration result.

The simulation results when sensors are close to each other.

A further performance analysis of this algorithm is done with the simulation environment in (Helmick and Rice, 1993) which is denoted as Helmick's algorithm. The parameters of the sensors are same with that in Helmick's algorithm.

Because only the track distribution figures of the targets are shown and the movement parameters of the targets are not given in detail in Helmick's algorithm, the simulation movement parameters of the targets in this study is almost consistent with that in Helmick's algorithm, which is shown in Fig. 8.

Figure 9-13 are the RMS curves of the relative bias estimations by the algorithm in this study and Helmick's algorithm with twenty Monte Carlo simulations, where the calculation of the relative bias estimations is consistent with that in Helmick's algorithm and $\varepsilon r=\varepsilon_{\mathrm{r}_{2}}-\varepsilon_{\mathrm{r}_{1}}, \varepsilon \theta=\varepsilon_{\mathrm{a}_{2}}-\varepsilon_{\mathrm{a}_{1}}+\varepsilon_{\vartheta_{1}}-\varepsilon_{\vartheta_{2}}$, $\varepsilon \eta=\varepsilon_{\phi_{1}}-\varepsilon_{\phi_{2}}, \varepsilon \psi=\varepsilon_{\alpha_{1}}-\varepsilon_{\alpha_{2}}, \varepsilon \zeta=\varepsilon_{\mathrm{e}_{2}}-\varepsilon_{\mathrm{e}_{1}}$.
Figure 9-13 have shown that the estimation precision of the algorithm in this study is much better than that of the algorithm in reference Helmick's algorithm. This is mainly because a lot of linearization is applied in Helmick's algorithm, which could bring the calculation errors.

The absolute estimations of the biases with the algorithm in this study at the 200th sampling point (namely the 100th sec) are shown as follows:

$$
\begin{aligned}
& \varepsilon_{\mathrm{r}_{1}} 204.9 \mathrm{~m}, \varepsilon_{\mathrm{a}_{1}}=-0.35^{\circ}, \varepsilon_{\mathrm{e}_{1}}=-0.70^{\circ} \\
& \varepsilon_{\vartheta_{1}}=0.35^{\circ}, \varepsilon_{\phi_{1}}=1.17^{\circ}, \varepsilon_{\alpha_{1}}=-1.18^{\circ} \\
& \varepsilon_{\mathrm{r}_{2}}=229.0 \mathrm{~m}, \varepsilon_{\mathrm{a}_{2}}=1.64^{\circ}, \varepsilon_{\mathrm{e}_{2}}=0.79^{\circ} \\
& \varepsilon_{\vartheta_{2}}=-1.64^{\circ}, \varepsilon_{\phi_{2}}=-0.78^{\circ} \varepsilon_{\alpha_{2}}=0.87^{\circ}
\end{aligned}
$$

The simulation results above have shown that the bias estimations are almost consistent with their true values except for the distance bias estimation when the distances among the sensors are small. So the algorithm in this study can also implement the absolute registration of the biases except for the distance bias when the distances among the sensors are small.

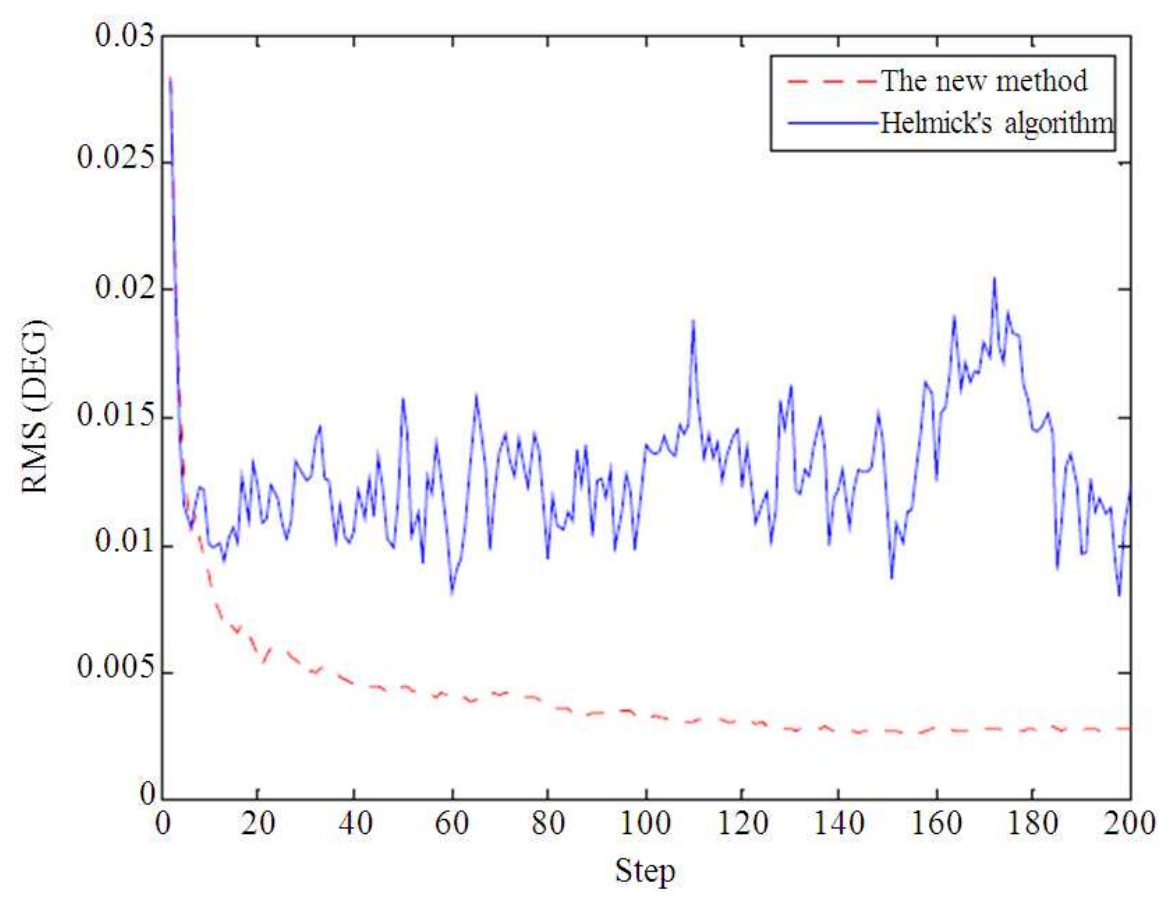

Fig. 10. Azimuth bias estimates 
Liu Yu et al. / Journal of Computer Science 9 (12): 1648-1660, 2013

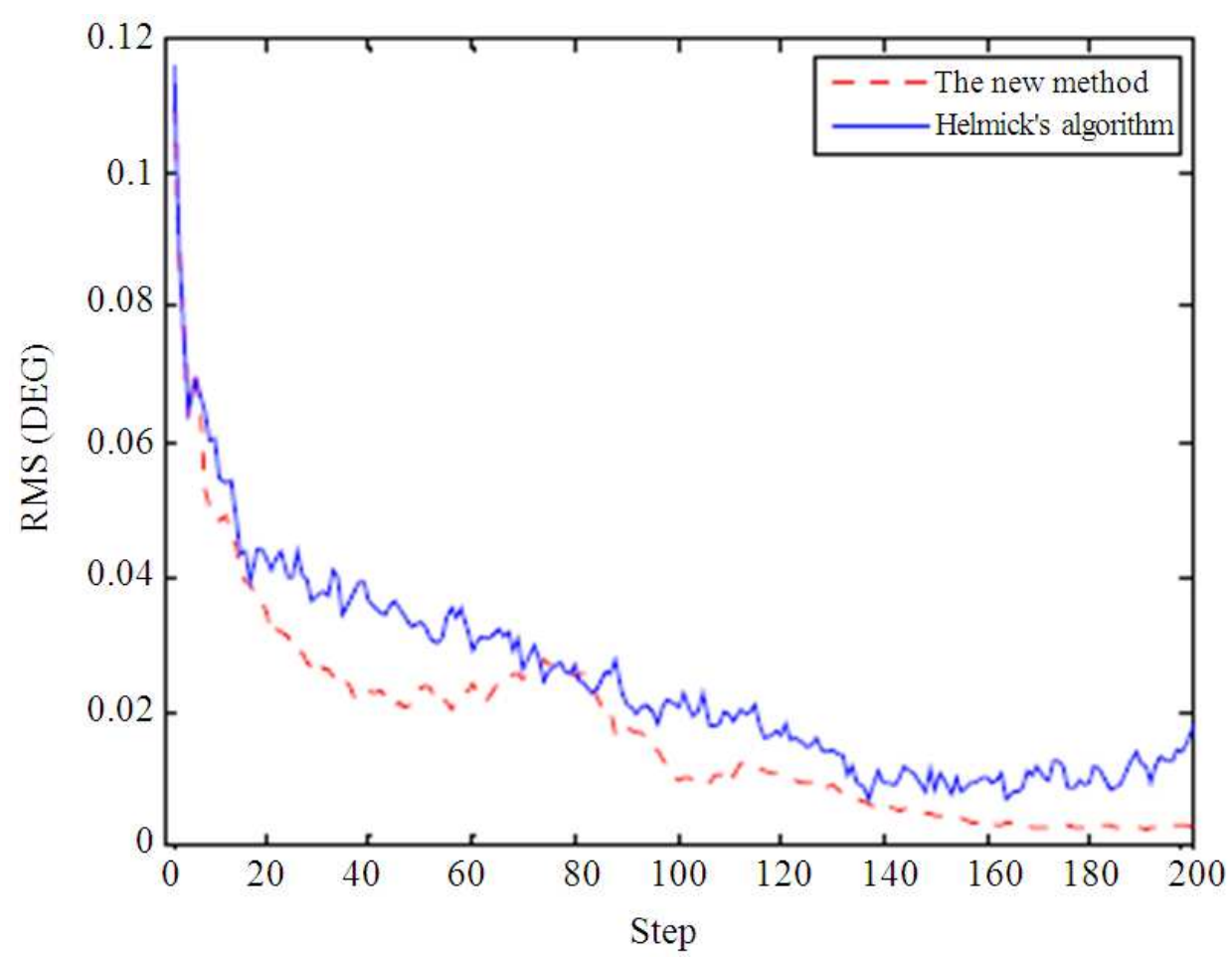

Fig. 11. Elevation bias estimates

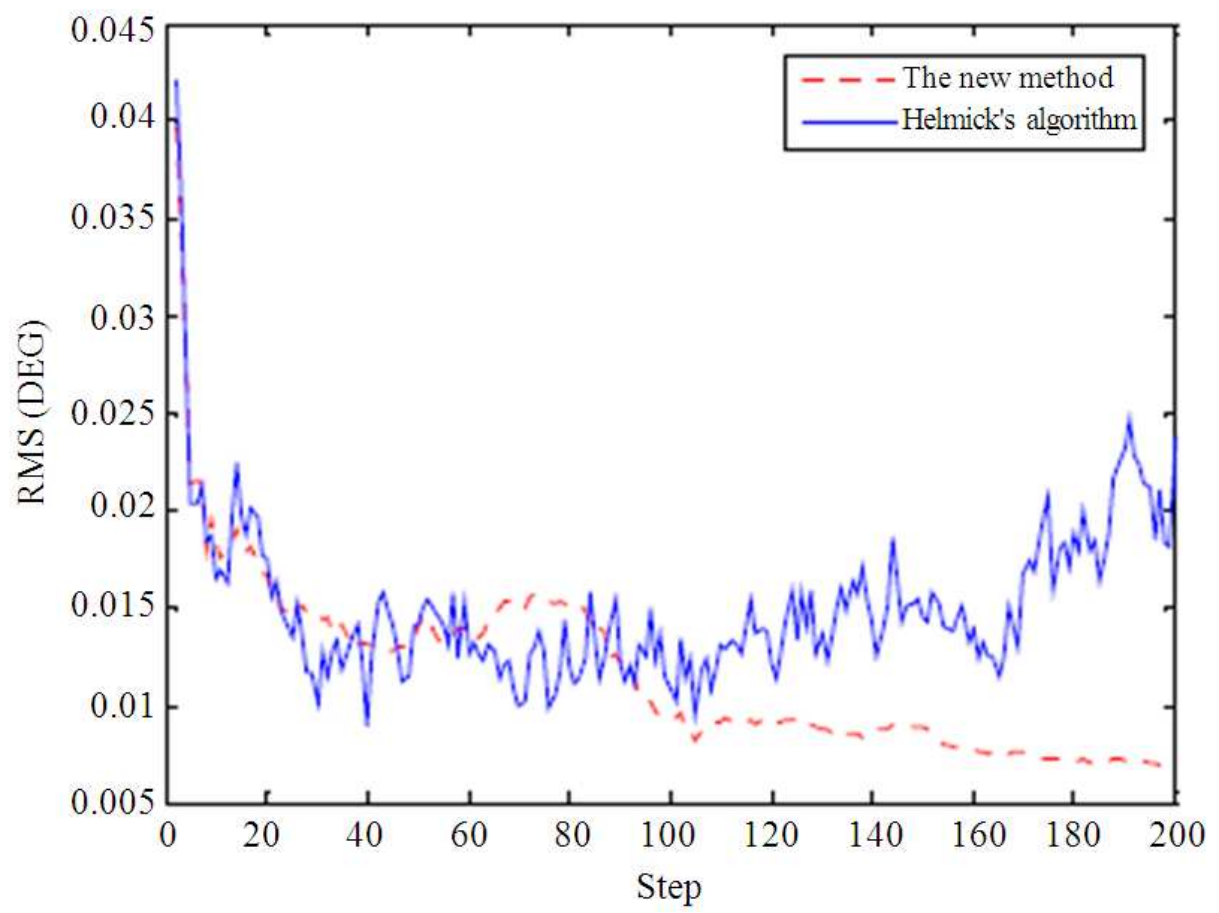

Fig. 12. Pitch bias estimates 


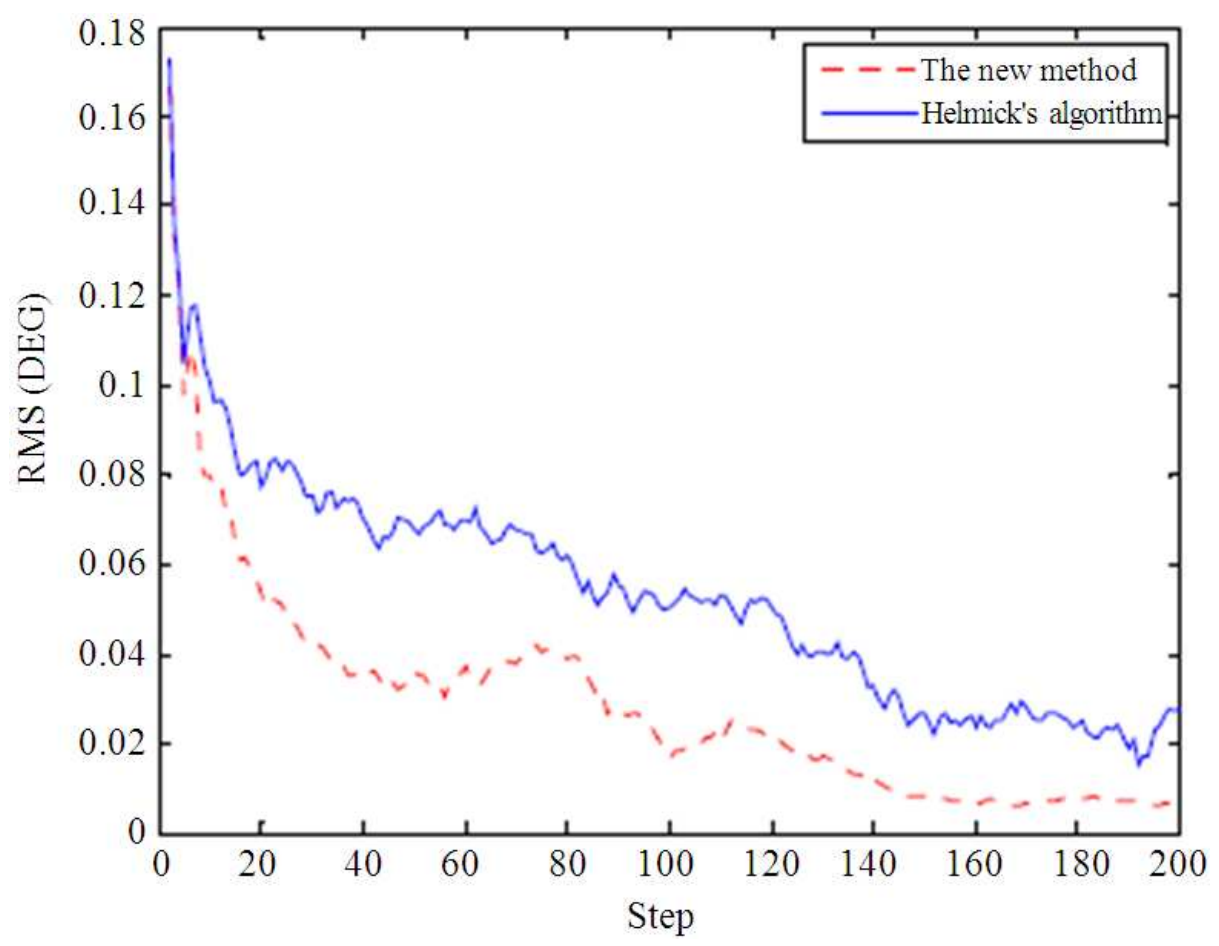

Fig. 13. Roll bias estimates

In the process of simulation, if the values of each kind of random measurement errors and the true target trajectories are changed, the results show that the RMS of bias estimations will be affected. This conclusion is in line with the conclusion of the past literatures.

In order to estimate all the biases, there are more than two observable targets in the common surveillance area and the targets must be located in two different quadrants (Barsholm, 2001). It is easily known that the proposed method can't guarantee the independent observability of some biases when the conditions as follows are met (Topland et al., 2007):

- The distance between two radars is very close (namely $\mathrm{T}_{2} \mathrm{~T}_{1} \approx \mathrm{I}$ ) and the attitude bias of two radars are same approximately

- The azimuth bias is equivalent to its carrier yaw bias approximately

- The elevation bias is equivalent to its carrier pitch bias approximately

- In such situations, the joint estimation of bias parameter should be done to guarantee the accuracy of bias estimation

\section{CONCLUSION}

This study presented a study of the registration algorithm for mobile 3-D radars with no location error. In the study, a modified unscented Kalman filter is proposed in order to estimate the radar attitude and measurement bias in real time. At last some numerical examples are used to demonstrate the main advantages and features of the algorithm. An important problem left unresolved is to estimate three dimensional location errors.

\section{ACKNOWLEDGMENT}

This study was supported by the National Natural Science Foundation of China (61032001) and Shandong Provincial Natural Science Foundation of China (ZR2012FQ004).

\section{REFERENCES}

Barsholm, Y., 2001. Airborne GMTI radar position bias estimation using static-rotator targets of opportunity. IEEE Trans. Aerospace Electr. Syst., 37: 695-699. DOI: $10.1109 / 7.937480$ 
Bo, W., L. ZhiGang and L. YueDong, 2006. A real-time alignment algorithm based on kalman filter. Proceedings of the 1st International Symposium on Systems and Control in Aerospace and Astronautics, Jan 19-21, IEEE Xplore Press, Harbin, pp: 10141017. DOI: 10.1109/ISSCAA.2006.1627495

Burke, J.J., 1996. The sage real time quality control function and its interface with BUICII/BUICIII. MITRE Corporat. Tech. Report.

Crue, E.J.D., A.T. Alouani and T.R. Rice, 1992. Sensor registration in multisensor systems. Proceedings of the SPIE Signal and Data Processing of Small Targets, Aug. 25-25, SPIE, pp: 382-393. DOI: $10.1117 / 12.139386$

Dong, Y.L., Y. He and G.H. Wang, 2004. A modified exact maximum likelihood registration algorithm. Proceedings of the 3rd International Conference on Computational Electromagnetics and Its Applications, Nov. 1-4, IEEE Xplore Press, pp: 8588. DOI: 10.1109/ICCEA.2004.1459295

Farina, A. and F.A. Studer, 1986. Radar Data Processing. 2nd Edn., Research Studies Press, Letchworth, ISBN-10: 0863800386, pp: 362.

Helmick, R.E. and T.R. Rice, 1993. Removal of alignment errors in an integrated system of two 3D sensors. IEEE Trans. Aerospace Electr. Syst., 29: 1333-1343. DOI: $10.1109 / 7.259537$

Julier, S.J. and J.K. Uhlmann, 2000. A new method for the nonlinear transformation of means and covariances in filters and estimators. IEEE Trans. Automatic Control, 45: 477-482. DOI: 10.1109/9.847726

Karmiely, H. and T.S. Hava, 2000. Sensor registration using neural network. IEEE Trans Aerospace Electr. Syst., 36: 85-100. DOI: 10.1109/7.826314
Kragel, D.B., D. Scott and M.H. Shawn, 2007. Bias estimation using targets of opportunity. Proceedings of the SPIE Signal and Data Processing of Small Targets, Sep. 21-21, SPIE, San Diego, CA., pp: 116. DOI: $10.1117 / 12.738161$

Lian, F., C. Han and W. Liu, 2011. Joint spatial registration and multi-target tracking using an extended probability hypothesis density filter. IET Radar Sonar Navigat., 5: 441-448. DOI: 10.1049/ietrsn.2010.0057

Mei, L., S. Sivananthan and R. Sittler, 2006. A new multi-sensor registration. Proceedings of the IEEE Conference on Radar, Apr. 24-27, IEEE Xplore Press, pp: 788-794. DOI: 10.1109/RADAR.2006.1631893

Ong, H.T., 2003. Sensor registration using airlanes: Maximum likelihood solution. Proceedings of the SPIE Signal and Data Processing of Small Targets, Dec. 30-30, SPIE, San Diego, California, pp: 390401. DOI: $10.1117 / 12.502491$

Topland, M.P., O. Hallingstad, A. Sinha and T. Kirubarajan, 2007. Bias estimation for distributed radars in 3D. Proceedings of the IEEE Aerospace Conference, Mar. 3-10, IEEE Xplore Press, Big Sky, MT., pp: 1-9. DOI: 10.1109/AERO.2007.353053

You, H., X. Jianjuan, Z. Jinwei and G. Xin, 2005. Radar Data Processing and Application. 1st Edn., Electronic Industry Press.

You, H., Z. Hongwei and T. Xiaoming, 2013. Joint systematic error estimation algorithm for radar and automatic dependent surveillance broadcasting IET Radar, Sonar Navigat., 7: 361-370. DOI: 10.1049/iet-rsn.2012.0199

Yunlong, H.Y. and W. Guohong, 2005. An new algorithm of realtime registration of radar network. J. Nanjing Univ. Aeronaut., 37: 330-334. 